\title{
A Peer Review Training Workshop: Coaching Students to Give and Evaluate Peer Feedback
}

Ricky Lam

In this article, I demonstrate how I planned and conducted a peer review training workshop to coach my students in giving and responding more effectively to peer feedback. The recommended training approach aims to raise students' consciousness through analyzing the effectiveness of their peer feedback and evaluating the extent to which peers' comments are incorporated into their subsequent revisions.

Dans cet article, je démontre comment j'ai planifié et mis en oeuvre un atelier de formation en révision par les pairs pour entraîner mes étudiants à offrir une meilleure rétroaction à leurs pairs et à y réagir de façon plus efficace. L'approche que je recommande vise à rehausser la conscience des étudiants en analysant l'efficacité de la rétroaction de leurs pairs et en évaluant la mesure dans laquelle les commentaires des pairs son intégrés dans leurs révisions subséquentes.

\section{Introduction}

Peer review, one of the constructivist approaches to writing instruction, has been commonly adopted in both L1 and ESL/EFL teaching contexts since the early 1980s (Bartels, 2003; Bruffee, 1984; Ferris, 2003; George, 1984; Hu, 2005; Lee, 1997; Liu \& Sadler, 2003; Lundstrom \& Baker, 2009). Pedagogically defined, peer review assumes that students play the role of trained peer reviewers whose task is to give a commentary on their partners' initial drafts in either written or spoken mode during composition lessons (Hansen \& Liu, 2005). It is popular mainly because such an approach to writing instruction is affectively, cognitively, and linguistically beneficial to students' writing development (Berg, 1999; Hu; Min, 2005; Rollinson, 2005). However, despite these advantages, the current literature in support of the usefulness of peer review activities is inevitably undermined by some empirical evidence indicating a low ratio of incorporation of peer feedback into students' subsequent revisions (Miao, Badger, \& Zhen, 2006; Min, 2006; Paulus, 1999; Tsui $\& \mathrm{Ng}, 2000)$. The effectiveness of adopting peer feedback for enhanced revisions, therefore, has been called into question given that some ESL/EFL students believe that peer feedback-as opposed to teacher feedback or self-generated feedback - may be neither reliable nor professional enough to use (Hu; Leki, 1990; Min; Sengupta, 1998; Tsui \& Ng). In order to make peer review a successful classroom activity that helps students improve the 
quality of their revisions, studies centering on the effect of trained peer review on students' revision and writing quality have been burgeoning (Berg, 1999; Lundstrom \& Baker, 2009; Min, 2005, 2006; Paulus, 1999; Rollinson).

There is no denying that trained peer review, as illustrated in a plethora of peer review or peer response scholarship, has a positive effect on students' writing in general and on improved revision quality in particular (Berg, 1999; $\mathrm{Hu}$, 2005; Min, 2006; Paulus, 1999; Stanley, 1992). From these studies, it is evident that trained peer feedback does have a significant role to play in helping to improve students' interim and final drafts. Nonetheless, whether these quality-enhancing revisions were due to the trained peer review itself or to students' self-revision during the writing process is not fully understood (Min; Suzuki, 2008). Unlike Berg's study, which compared the effect of one trained and another untrained peer review group on ESL students' revision types and quality, Min investigated the extent to which trained peer review feedback was actually incorporated into students' revisions and whether the number of peer-influenced revisions would be higher than that before peer review training. In other words, Min intended to look into whether trained peer review activities had a direct influence on students' revision quality via minute text analysis including type, size, and function of revisions. With both qualitative and quantitative data analysis, Min concluded that planned and trained peer review could directly have an effect on EFL students' revision types and overall quality of texts.

Inspired by Min's (2006) and Berg's (1999) studies, I illustrate how I planned and organized a training workshop for a group of 30 university freshmen non-English majors to help them analyze the effectiveness of peer feedback according to its area (i.e., local or global), nature (i.e., revisionoriented or non-revision-oriented), and type (i.e., evaluation, clarification, suggestion, or alteration). The coding of peer feedback in relation to its (a) area is divided into global and local. Global areas refer to feedback about the content, idea development, purpose, and organization of writing, and local areas refer to feedback about mechanics, grammar, and punctuation. Then peer feedback is further analyzed based on its (b) nature, namely, revisionoriented or non-revision-oriented, and (c) type. There are four types of peer feedback. Evaluation refers to judgments made by the peer reviewer on his or her partner's writing, but it provides no hints for further improvement. Clarification elicits explanations of those ideas that the peer reviewer does not understand and is usually in the form of interrogative statements. Suggestion means that the peer reviewer provides useful feedback to help the writer to make appropriate corrections, and alteration refers to errors that are directly or explicitly corrected by the peer reviewer; this type of peer comment is by far the most common in students' peer marking (Liu \& Sadler, 2003). The purpose of the workshop was to raise students' consciousness in order to 
master skills in giving specific and effective peer feedback, and eventually to help them incorporate peer comments into their own writing for better performance on graded writing assignments (Ellis, 2003, 2008).

\section{Context}

\section{Problems to be Addressed}

Having tried out peer review for two consecutive semesters in the previous academic year, I realized that the outcome had not been as satisfactory as expected. After conducting a focus group interview with six students whose English proficiency ranged from slightly above average to slightly below average, I understood that students found it difficult to give specific feedback to their peers, even though initial training on giving various types of peer feedback had been provided. Neither were they appreciative of the usefulness of such peer comments due to their failure in analyzing and interpreting them for use. While marking students' work and carrying out random checks on whether they had incorporated peer comments into their final drafts, I was disappointed to observe that fewer than half the peer comments were adopted in the form of actual revisions. In view of students' inability to give effective peer comments, and the low incorporation rate of peer feedback into their subsequent revisions, I intended to plan a training workshop that would be more systematic than the existing one so as to better facilitate students' incorporation of useful peer feedback into their final drafts.

\section{Participants}

Thirty non-English majors agreed to attend this training workshop. They were enrolled in a foundation writing course designed specifically for all Year 1 students at a Hong Kong university, regardless of their English proficiency or public examination results (i.e., Use of English [UE] in the Hong Kong Advanced Level Examination [HKALE] for grade 12 students in the territory). The International English Language Testing System (IELTS) results of these 30 participants ranged from 6.0 to 6.5 , and they were on average low-intermediate L2 English-learners. They were all Cantonesespeakers, using English only for the purpose of academic studies and seldom speaking or writing English at home or in their social lives. Their average age was 19 when the workshop was held. None of these 30 participants had experienced peer review activities prior to this workshop.

\section{Writing Course}

The students' 30-week foundation writing course was a one-year mandatory for-credit module in which every Year 1 student had to enroll. Its focus was to develop students' writing abilities in various genres: specifically, expository essays in preparation for writing academic essays in such content 
disciplines as mathematics, the social sciences, or the humanities. Participants needed to take the writing course once a week, each class lasting three hours. Fifty minutes of the three hours were allotted to students for peer review activities. In addition to the first three weeks of peer review training, participants were expected to submit three essays of 500 words each in a writing portfolio, together with a reflective essay in each semester. In the discussion below, I describe the peer review training process. It consisted of three phases: the modeling stage, the exploring stage, and the consciousnessraising stage, which allowed me to provide the 30 students with sufficient training and scaffolding before the actual peer review activity.

\section{Peer Review Training}

This three-tier peer review training workshop lasted for three weeks and took place during the last hour of the first three three-hour tutorials in the first semester. The flow of the training workshop is as follows.

\section{Modeling Stage: Week 1}

First, I introduced and defined peer review. I then explained to students the purpose of adopting peer review activities in this writing course. While briefing students about the benefits of peer review for writing, I also shared with them the objectives of this training workshop: to equip attendees with sufficient revising skills to complete peer review tasks and to raise their awareness in giving effective peer feedback to their course mates.

Next I introduced and demonstrated a four-step procedure adapted from Min's (2005) study to prepare students for the peer review session. This four-step procedure is exemplified in Table 1.

Among the four procedures, according to Min (2006), explaining the nature of errors and providing feasible suggestions were the crucial steps in helping writers to make further modifications of their drafts, because without a sound justification, writers may be unconvinced of the need to adopt peer comments in their revisions. Worse still, students would simply ignore peer feedback lacking logical reasoning.

Having students understand how to attend to content errors during the first reading of their partners' drafts, I then shifted their focus to error corrections. At this stage, students were shown how they handled language errors more specifically. Adopting Ferris's (1999) notion of treatable and non-treatable errors, I attempted to make students aware that some errors were more treatable and accessible than others. According to Ferris, treatable errors tend to be more rule-governed so that peer reviewers may find it easier to explain the nature of these errors; moreover, she discusses examples of treatable errors, which mainly consist of verb-related categories such as tense, form, passives, modal use, and so forth. On the other hand, errors related to prepositions, sentence patterns, and unidiomatic phrases are 
Table 1

Four-Step Procedure

\begin{tabular}{|c|c|c|c|}
\hline & Procedure & Purpose & Examples \\
\hline 1. & Clarifying & $\begin{array}{l}\text { To elucidate writer's } \\
\text { intentions }\end{array}$ & $\begin{array}{l}\text { "Do you want to say ..." } \\
\text { "Could you explain why you think ..." } \\
\text { "Do you mean that ..." } \\
\text { "What is the purpose of this paragraph?" } \\
\text { "Why did you put ... in this paragraph?" }\end{array}$ \\
\hline 2. & Identifying & $\begin{array}{l}\text { To search for } \\
\text { problematic areas }\end{array}$ & $\begin{array}{l}\text { "Do you realize that ... and ... are } \\
\text { incompatible?" } \\
\text { "It sounds to me that this issue you presented } \\
\text { is too subjective." } \\
\text { "It seems to me that ... and ... should not be } \\
\text { compared in this dimension." }\end{array}$ \\
\hline 3. & Explaining & $\begin{array}{l}\text { To describe the nature } \\
\text { of problems }\end{array}$ & $\begin{array}{l}\text { "You may be wrong here because ..." } \\
\text { "This example may not be suitable to illustrate } \\
\text { the idea of the topic sentence." } \\
\text { "This quote may not be relevant to what you } \\
\text { are discussing. You should say ... instead." }\end{array}$ \\
\hline 4. & $\begin{array}{l}\text { Giving } \\
\text { suggestions }\end{array}$ & $\begin{array}{l}\text { To provide workable } \\
\text { suggestions for } \\
\text { modifications }\end{array}$ & $\begin{array}{l}\text { "Why don't you change the idea from ... to } \\
\text {...?" } \\
\text { "I think you should give more information } \\
\text { about ... in the second-last paragraph?" } \\
\text { "You might use the word ... rather than ..." } \\
\text { "You need to add a phrase concerning the } \\
\text { disadvantages of ... here." }\end{array}$ \\
\hline
\end{tabular}

labeled as non-treatable because they are difficult for peer reviewers to explain or address by suggesting correction tips unless the correct answers are provided directly to the writers. If feedback generated by peer reviewers is mainly of a non-treatable nature, its effectiveness will be reduced, so that reviewers are strongly recommended in the peer review sessions to identify and explain treatable errors first. Attention to content and language errors based on the assigned scoring rubrics was also prioritized. The former came before the latter in order to give students an impression that the content of a piece of writing was always as significant as its form. For example, I instructed peer reviewers to start examining coherence and argumentation in their partners' work before diligently editing any linguistic errors. Finally, I briefed students on the procedural guidelines for how a formal peer review session is to operate (see Appendix A).

Exploring Stage: Week 2

After going through the modeling stage, students were invited to practice the four-step procedure with some authentic exemplars collected from writing 
samples composed by students studying in the previous cohort of the same writing course. This hands-on practice aimed to assess how well the students were able to identify both content and language errors and accordingly explain them and provide their peers with appropriate suggestions for modification. Following the questions suggested on the guidance sheet for peer reviewers, students were expected to write and number the content errors on the exemplars according to their order of occurrence (see Appendix B). After this, they were expected to read the exemplars again to look for such language errors as wrong use of verb tenses and misspelling. Having finished the procedure for the identification of both content and language errors in the exemplars, students exchanged their exemplars with their partners, discussed the quality of the peer marking, and checked if they had missed any errors. I invited a few dyads, depending on the availability of class time, to talk about their peer marking to the whole class in order to help deepen students' understanding of the four-step procedure. Last, I completed the second part of the training session and further clarified any misunderstandings arising from students' presentations by providing appropriate explanations.

\section{Consciousness-Raising Stage: Week 3}

In Week 2 I taught the first writing genre-categorization-and attempted to use the first drafts of this genre as writing samples for the training workshop in the following week. For the purpose of training, students were not asked to write a full-length essay of 500 words. Instead they were asked to write a mini-essay (the first draft) in the genre of categorization as an assignment after the Week 2 tutorial and were expected to bring it to class in Week 3 to continue with their training.

The consciousness-raising stage was the most salient step of the training workshop because students were trained to analyze the peer feedback that they gave to their partners and further examine its effectiveness through keeping a peer review $\log$ (see example in Appendix C). Similarly, as writers they were also coached to analyze the extent to which they had responded to the peer feedback they themselves had received and to evaluate whether the suggestions offered by peer reviewers were incorporated into their own revisions (Appendix C). This final stage emphasized raising students' consciousness; it aimed to help them to engage more autonomously in peer review activities despite the much-needed teacher intervention at the outset of the training process. When students played the role of peer reviewers, they were taught how to code the peer comments that they generated in terms of three aspects: (a) area (global or local); (b) nature (revision-oriented or nonrevision-oriented); and (c) type (evaluation, clarification, suggestion or alteration). When they played the role of writers, they were taught how to keep track of the kinds of peer comments they received, analyze how much peer 
feedback they had incorporated in their first revision, and investigate why certain peer feedback could not be incorporated.

Because this consciousness-raising stage was somewhat cognitively demanding, I arranged conferences with each pair of students to monitor whether they could manage to keep their peer review logs properly. The conferences were held over three days after the third tutorial, the last phase of the peer review training. Each conference lasted about 20 minutes. Unlike in Min's (2006) teacher-reviewer conferences, I expected students to raise questions about their uncertainties when categorizing peer feedback and their concerns about how to respond to it. I gave assistance to students in analyzing peer feedback and taught them how to make better revisions based on peer comments, but my approach was more student-fronted and avoided falling into the teaching trap of dominating the discourse of the conference as if I were reteaching parts of the course content (Brown, 2004).

\section{Instructor's Reflection}

In order to collect views on how students responded to the peer review training workshop, I conducted a 30-minute post-workshop interview with four students whose academic abilities ranged from above average to slightly below average. This semistructured interview was conducted in Cantonese, translated and transcribed into English (see Appendix D). Judging by their viewpoints, these participants were generally positive about the use of peer review activities in the writing course and the training they had received about not only how to give effective peer feedback to their partners, but also how to evaluate how successfully peer feedback was incorporated into their own subsequent revisions. Two students felt that the training was practical: The training is practical because we mastered the skills in giving effective peer feedback. And one student even pointed out the significance of giving specific feedback: It [the training] lets me know the importance of giving specific and revisable feedback to my peers since vague comments are not useful for quality revisions. Another remarked that he had learned how to give effective feedback after attending the workshop: I have learned how to give appropriate peer comments to my classmates. Prior to the workshop, I thought "Well done" or "Need to improve grammar" was good-enough peer feedback.

The interview data also indicated that students who themselves were critical about their peers' work would become even more critical of their own writing if they were able to internalize the editing and revising skills acquired in the peer review training workshop. As two students said, The training in giving peer feedback makes us understand that if we can judge other compositions, it is likely for us to develop a judicious mind in critiquing our own work in a similar manner. Moreover, students found the peer review log a useful tool to reflect on the revision process and to examine the effectiveness of revisions made in their writing. One student observed: Not only does the 


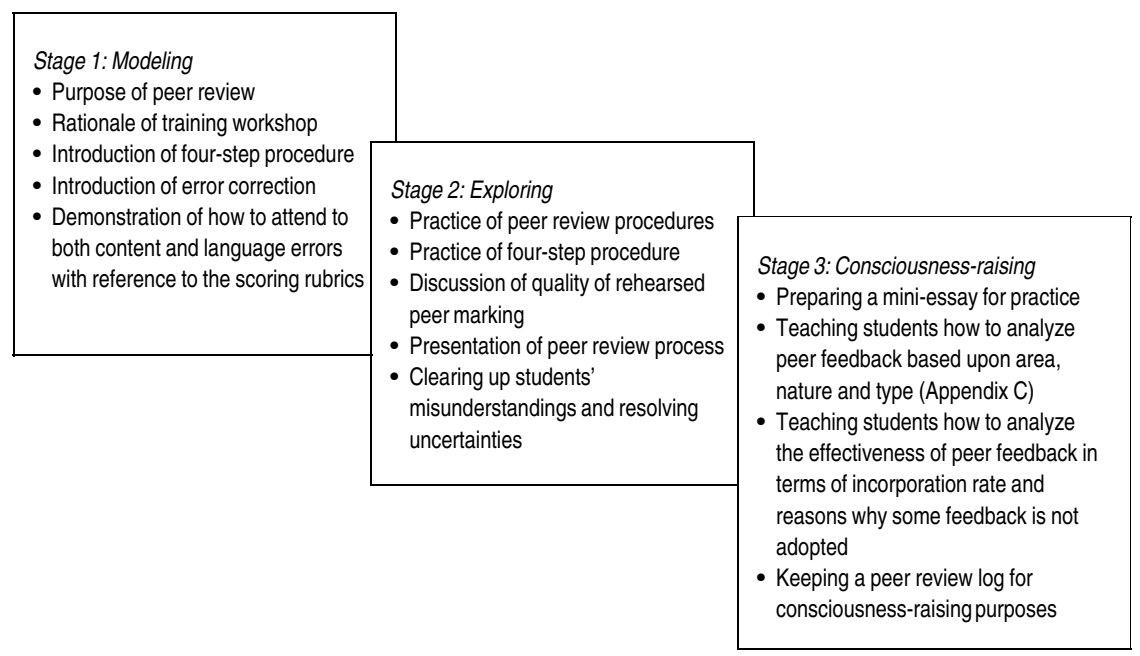

Figure 1. Peer review training.

peer review log give students insights into how revision-in-progress is operated, but also it allows them to monitor the quality of revisions.

However, one concern raised by two interviewees in relation to the use of the peer review log was that students might have spent extra time analyzing the received peer feedback on top of their busy schedule of coursework: One drawback of peer review log is that we need to use extra time to process the peer feedback, which means our workload will be doubled this semester and Despite the usefulness of the peer review log, I reminded myself of taking students' workload into consideration, so as to make peer reviews an enjoyable not a grueling writing activity in the classroom.

In retrospect, the training workshop was well received and did equip students with the basic revising skills needed for conducting successful peer review activities. Nonetheless, the success of peer review in the writing classroom largely rests on students' belief in the usefulness of peer feedback, their prior knowledge about the inclusion of peer feedback in the writing process, and their linguistic competence in interpreting and using peer feedback in their actual revisions. The quality of peer review training, meanwhile, should also be borne in mind if writing teachers wish to make peer review a useful and productive learning activity. Training in how to generate specific peer feedback and in how to examine its effectiveness no doubt plays a vital role in advocating peer review in the L2 writing classroom.

As revealed by Rollinson (2005), teacher intervention is also one of the contributing factors that make the implementation of peer review activities profitable in the classroom. However, based on my observation, it is necessary to strike a balance between teacher intervention and teacher support. 
The former notion refers to direct and top-down assistance given to students collectively, without considering the needs of individual students; the latter concept refers to more context-sensitive and personalized assistance offered to specific students when they participate in the peer review process. Rollinson's focused intervention training in his study may have been too top-down and teacher-centered such that students might become too reliant on teacher assistance rather than taking more initiative in giving peer feedback to their partners. On the other hand, teacher support if used appropriately in peer review training or activities could motivate students to think more critically and independently about the comments they wish to make to their partners, and the teacher's role might be reduced to giving professional suggestions and clearing up any uncertainties about particular certain linguistic problems. Hence the degree of teacher involvement in training for peer review deserves much more attention than might at first glance seem necessary in order to foster students' autonomy in the activity.

\section{Recommendations for Effective Peer Review Training}

Having tried out this peer review training workshop, I realized that if writing teachers intend to make peer review successful and beneficial for their students, it is imperative to plan each procedure carefully and to provide proper training. To foster better implementation of peer review activities in the writing classroom, practical suggestions on peer review training are proposed as follows. These recommendations are not meant to be exhaustive, but they are based on the my observations, the experience gained from piloting the training workshop, and relevant literature that I studied in relation to $\mathrm{L} 2$ peer reviews.

\section{Use of Scoring Guides}

Because students usually encounter difficulties with prioritizing the marking of content or language errors, or even do not know what they should target while commenting on their peers' papers, teachers should make use of effective scoring guides as a starting point and then help students understand on what they are expected to focus in their peer marking through these guides. Consequently, when students are doing peer evaluation, they can rely on both the vocabulary and the scale itself to make sound judgments of their peers' work (White, 2007). Vague and rubber-stamp comments can easily be avoided if scoring guides are adopted during the peer review session. Teachers may also consider inviting students themselves to construct part of the scoring guides in order to help them internalize the assessment criteria, which in turn can help them give more effective peer feedback to their classmates. 


\section{Promotion of Self-Editing}

Students should be trained to be responsible for applying editing strategies in their own work before undertaking peer evaluation. If they are more accountable for editing their own language errors before participating in the peer review activity, peer reviewers can attend specifically to any content errors in their partners' writing and may generate more constructive feedback for effective revisions. Having students write a reflective statement about which of the editing strategies they adopted and found most useful after completing each piece of work may be a good option to facilitate practical editing strategies, and these strategies should mesh with trained peer reviewing as part of the overall writing process (Ferris, 2008). Having students assume more responsibility for editing their own work before peer review would also reduce the workload of the peer reviewers, as well as making the event more efficient and successful.

\section{Support by Technology}

Making use of technology to assist with peer review training could be a viable strategy (Liu \& Sadler, 2003). Often teachers may feel that there is insufficient time for students to comment on one another's drafts in class, despite the numerous advantages peer review could render to students. Given that class time for teachers to deliver writing instruction is limited, teachers may consider extending peer review training or practice outside the classroom or even off campus through Web 2.0 applications to help students give and receive peer feedback on line. For example, blogs and wikis are two commonly used free Web resources that can enhance better communication not only among teachers and students, but also among students and the wider learning community such as parents or seniors in the school (Sankofi, 2008). Blogs may encourage students to give more serious and objective peer feedback because their comments are viewed by a larger audience than just their work partners, and wikis are particularly facilitative for students who wish to give peer feedback to more than one writer or who prefer frequent revisions of their drafts with minimal effort (Penrod, 2007).

\section{Conclusion}

As part of process-oriented writing instruction, peer review has been widely adopted in L1 and ESL/EFL writing classrooms despite its potential pitfalls such as low reliability and insignificant effect on the quality of students' revisions. These shortcomings could be resolved by means of sufficient and systematic training for students before the implementation of peer review so that they become more competent in analyzing their own peer feedback and assessing whether this feedback is effective for subsequent revisions. As illustrated above, peer review training workshops have a role to play in 
helping students become not only better peer reviewers, but also conscientious writers who take responsibility for editing their own work. Trained peer review activity is an organic learning activity that supports students in developing writing abilities interactively, as well as empowering them to participate actively in the wider learning community. Teachers interested in peer review may consider adapting this three-tier training procedure to their own teaching contexts, provided they have administrative support such as autonomy in designing the English curriculum and with appropriate consent from students. In addition, the rationale and benefits of peer review should be well communicated to students and other stakeholders, for example, parents or school administrators, in order to encourage them to give further support to teachers in promoting this rewarding L2 writing activity.

\section{The Author}

Ricky Lam is a teacher trainer in the Department of English at the Hong Kong Institute of Education. He is currently a part-time doctoral student at the University of Hong Kong. His research interests are in L2 writing assessment, portfolio assessment, peer review, and assessment for learning.

\section{References}

Bartels, N. (2003). Written peer response in L2 writing. English Teaching Forum, 41(1), 34-37.

Berg, E.C. (1999). The effects of trained peer response on ESL students' revision types and writing quality. Journal of Second Language Writing, 8, 215-241.

Brown, H.D. (2004). Language assessment: Principles and classroom practices. New York: Longman.

Bruffee, K. (1984). Collaborative learning and the "conversation of mankind." College English, $46,635-652$.

Ellis, R. (2003). Task-based language learning and teaching. Oxford, UK: Oxford University Press.

Ellis, R. (2008). The study of second language acquisition (2nd ed.). Oxford, UK: Oxford University Press.

Ferris, D.R. (1999). The case for grammar correction in L2 writing classes: A response to Truscott (1996). Journal of Second Language Writing, 8, 1-11.

Ferris, D.R. (2003). Response to student writing: Implications for second language students. Mahwah, NJ: Erlbaum.

Ferris, D.R. (2008). Students must learn to correct all their writing errors. In J. Reid (Ed.), Writing myth: Applying second language research to classroom teaching (pp. 90-114). Ann Arbor, MI: University of Michigan Press.

George, D. (1984). Writing with peer groups in the composition classroom. College Composition and Communication, 35, 320-326.

Hansen, J.G., \& Liu, J. (2005). Guiding principles for effective peer response. ELT Journal, 59(1), 31-38.

Hu, G. (2005). Using peer review with Chinese ESL student writers. Language Teaching Research, 9, 321-342.

Lee, I. (1997). Peer reviews in a Hong Kong tertiary classroom. TESL Canada Journal, 15(1), 58-69.

Leki, I. (1990). Potential problems with peer responding in ESL writing classes. CATESOL Journal, 3, 5-17.

Liu, J., \& Sadler, R.W. (2003). The effect and affect of peer review in electronic versus traditional modes on L2 writing. Journal of English for Academic Purposes, 2, 193-227. 
Lundstrom, K., \& Baker, W. (2009). To give is better than to receive: The benefits of peer review to the reviewer's own writing. Journal of Second Language Writing, 18(1), 30-43.

Miao, Y., Badger, R., \& Zhen, Y. (2006). A comparative study of peer and teacher feedback in a Chinese EFL writing class. Journal of Second Language Writing, 15, 179-200.

Min, H.T. (2005). Training students to become successful peer reviewers. System, 33, 293-308.

Min, H.T. (2006). The effects of trained peer review on EFL students' revision types and writing quality. Journal of Second Language Writing, 15, 118-141.

Paulus, T.M. (1999). The effect of peer and teacher feedback on student writing. Journal of Second Language Writing, 8, 265-289.

Penrod, D. (2007). Using blogs to enhance literacy: The next powerful step in 21st century learning. Lanham, MD: Rowman \& Littlefield Education.

Rollinson, P. (2005). Using peer feedback in the ESL writing class. ELT Journal, 59(1), 23-30.

Sankofi, M. (2008). Web 2.0 in the language classroom. Essential Teacher, 5(4), 34-36.

Sengupta, S. (1998). Peer evaluation: "I am not the teacher." ELT Journal, 52(1), 19-28.

Stanley, J. (1992). Coaching student writers to be effective peer evaluators. Journal of Second Language Writing, 1, 217-233.

Suzuki, M. (2008). Japanese learners' self revisions and peer revisions of their written compositions in English. TESOL Quarterly, 42, 209-233.

Tsui, A.B.M., \& Ng, M. (2000). Do secondary L2 writers benefit from peer comments? Journal of Second Language Writing, 9, 147-170.

White, E.M. (2006). Assigning, responding, evaluating: A writing teacher's guide (4th ed.). Boston/New York: Bedford/St. Martin's.

\section{Appendix A. Procedures Concerning the Operation of Peer Review Sessions}

1. In pairs, exchange your first draft in the genre of categorization (e.g. nations or careers) with your partner and read it in detail.

2. Use a pencil to annotate your partner's work in the areas of thesis statement, topic sentences, developing ideas and organization in various paragraphs.

3. Jot down your comments and suggestions in the order of occurrence and number the comment/suggestion one after another on the margins.

4. Then, read the draft again and identify some common and "treatable" grammatical errors with a highlighter and a ball-point pen. Do not correct the language errors. Underline or circle those errors with the appropriate error codes.

5. Point out all language and content errors on the draft. If you have doubt about some errors, feel free to contact me. Having entered all your comments, please also record these comments in Part 1 of your peer review log for analysis; then, sign at the bottom of the draft and pass it back to your partner.

6. Let your partner silently read your comments for about 5 to 10 minutes. Then, you need to clarify any points you are not clear about in your partner's work and invite him or her to explain the problematic areas to you.

7. In the meantime, your partner should also explain to you why he or she thinks particular feedback points are inappropriate for his/her draft if necessary.

8. Having received peer feedback from your partner, you (as a writer) need to read all the comments and raise questions if you are not certain about some feedback points. Then, start revising your first draft based upon the feedback, enter any revisions made in Part 2 of the peer review log, and analyze how much peer feedback you have incorporated in the subsequent revision and work out why some feedback cannot be adopted. 


\section{Appendix B. Guidance Sheet for Peer Reviewers}

A. What is the thesis statement in the introductory paragraph?

B. Is the introductory paragraph interesting and clearly written?

Attend to the following questions (C-E) when checking from the second to the fifth paragraphs:

C. What are the topic sentences in each paragraph and are they supported by developing ideas?

D. What are the supporting details for the main idea in each paragraph? If you cannot identify them, please suggest one for your partner.

E. Has your partner used any real life examples or concrete illustrations to support the main idea of each paragraph? If not, please provide him/her with directions to explain the main ideas with solid examples.

F. What is the target audience of the essay?

G. Have the issues of the essay been appropriately addressed?

$\mathrm{H}$. Is the essay coherent in terms of proper use of discourse markers or transitional signals to signpost various ideas?

I. Does the essay include the effective use of pronouns, paraphrasing, and synonyms in order to make the text cohesive (i.e. improving the texture of writing)?

J. Does the conclusion echo the thesis statement put forward in the introductory paragraph? Does the conclusion include relevant information highlighted in the previous paragraphs and moved to more general statements on the topic as a whole?

\section{Appendix C. Peer Review Log}

Part 1: Analysis of peer feedback given to the writer

Draft (4A)—essay on categorization

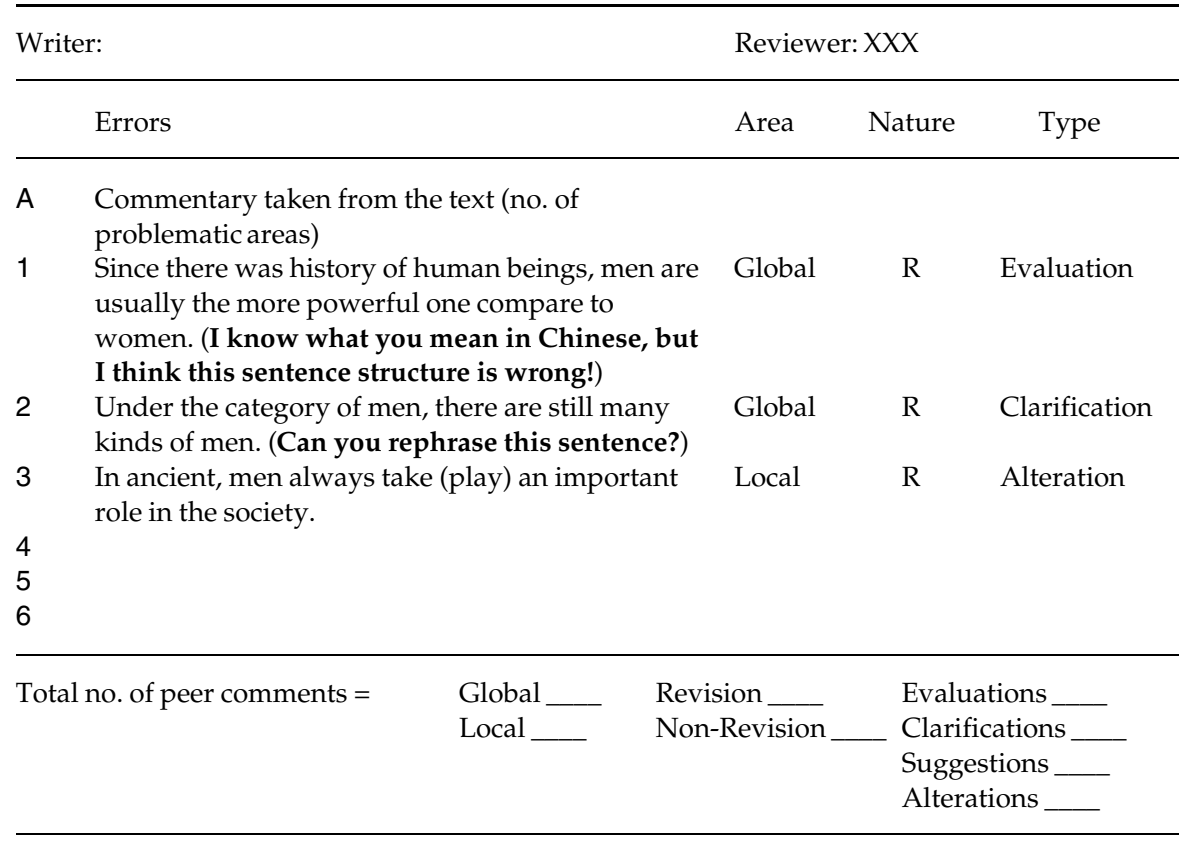


Part 2: Analysis of incorporation of peer feedback in revision

Draft 4B-essay on categorization (first revision)

\begin{tabular}{cll}
\hline Writer: XXX & \multicolumn{1}{c}{ Reviewer: } \\
\hline Errors & $\begin{array}{l}\text { No. of items revised } \\
\text { on Draft 4B and their } \\
\text { revisions }\end{array}$ \\
\hline
\end{tabular}

A Commentary taken from the text

1 Nations can be categorized into three types including developed countries, developing countries, undeveloped countries.

(The sentence is clear but lacks an organizing principle to guide the classification of various types of nations.

"Undeveloped countries" may be rephrased to "Underdeveloped countries.")

\begin{tabular}{|c|c|}
\hline $\begin{array}{l}1 \text { (Nations can be } \\
\text { categorized into three } \\
\text { types depending on } \\
\text { their economic } \\
\text { development } \\
\text { progress: developed } \\
\text { countries, developing } \\
\text { countries and }\end{array}$ & $\begin{array}{l}\text { I have added the } \\
\text { organizing principle } \\
\text { namely economic } \\
\text { development of the } \\
\text { country to classify } \\
\text { different nations and } \\
\text { put "and" between the } \\
\text { last two categories. }\end{array}$ \\
\hline
\end{tabular}
underdeveloped countries.)

2 The first kind which is the developed countries is wealthy and powerful in the world.

(Could you give a more specific definition of the developed countries?)

1 (The first category
which is the
developed countries
is usually wealthy,
strong in military
power and possesses
advanced technology.)

I have added two new ideas to the definition and make it more explicit.

3

4

5

6

No. of items revised on Draft $4 B=$

Total no. of peer comments $=$

Total no. of peer comments incorporated $=\quad$ incorporation rate $=\%$ No. of peer comments which are non-revision-oriented = Reasons why some peer comments are not adopted:

\section{Appendix D Student Interview Guide}

1. What do you think about the peer review training workshop?

2. Which aspects of the training workshop do you like most and why?

3. To what extent did you learn how to give effective feedback to your classmates through the training workshop?

4. What do you think about the peer review log?

5. What do you think about the workload of the training workshop? 